\title{
Superabsorbent Fibers for Comfortable Disposable Medical Protective Clothing
}

\author{
Lin Yang ${ }^{1,2} \cdot$ Hong Liu ${ }^{3} \cdot$ Shuai Ding ${ }^{1,2} \cdot$ Jiawei Wu ${ }^{4} \cdot$ Yan Zhang ${ }^{5} \cdot$ Zhongzhen Wang $^{1,2} \cdot$ Lili Wei $^{5} \cdot$ Mingwei Tian $^{3}$. \\ Guangming $\mathrm{TaO}^{4}$
}

Received: 30 March 2020 / Accepted: 12 May 2020 / Published online: 25 June 2020

(c) Donghua University, Shanghai, China 2020

\begin{abstract}
Disposable medical protective clothing for 2019-nCoV mainly consists of stacked layers with nanopore films, polymer coated nonwoven fabrics and melt-blown nonwoven fabrics against anti-microbial and anti-liquid penetration. However, such structures lack moisture permeability and breathability leading to an uncomfortable, stuffy wearing experience. Here, we propose a novel medical protective clothing material with a superabsorbent layer to enhance moisture absorption. Poly(acrylic acid-co-acrylamide)/polyvinyl alcohol superabsorbent fibers (PAAAM/PVA fibers) were prepared via wet spinning. And the superabsorbent composite layer was stacked from PAAAM/PVA fibers, bamboo pulp fibers (BPF) and ethylene-propylene side by side fibers (ESF). The novel disposable medical protective composite fabric was obtained through gluing the superabsorbent layer to the inner surface of strong antistatic polypropylene nonwoven fabric. The resultant composite fabric possesses excellent absorption and retention capacity for sweat, up to $12.3 \mathrm{~g} / \mathrm{g}$ and $63.8 \%$, and a maximum hygroscopic rate of $1.04 \mathrm{~g} / \mathrm{h}$, higher than that of the conventional material (only $0.53 \mathrm{~g} / \mathrm{h}$ ). The moisture permeability of the novel material reached $12,638.5 \mathrm{~g} /\left(\mathrm{m}^{2} \mathrm{~d}\right)$, which was $307.6 \%$ of the conventional material. The novel material can effectively reduce the humidity inside the protective clothing and significantly improve the comfort of medical staff.
\end{abstract}

Keywords Poly(acrylic acid-co-acrylamide)/polyvinyl alcohol superabsorbent fiber · Sweat absorption · Hygroscopicity nonwoven $\cdot$ Medical protective clothing $\cdot$ Thermal and moisture comfort

\section{Introduction}

The novel coronavirus (2019-nCoV) outbreak is a public health emergency of international concern (PHEIC) [1]. The virus is primarily spread by small droplets produced by talking, coughing or sneezing [2-5]. It is most contagious during the first three days after onset of symptoms, although

Lin Yang and Hong Liu equally contributed to this work.

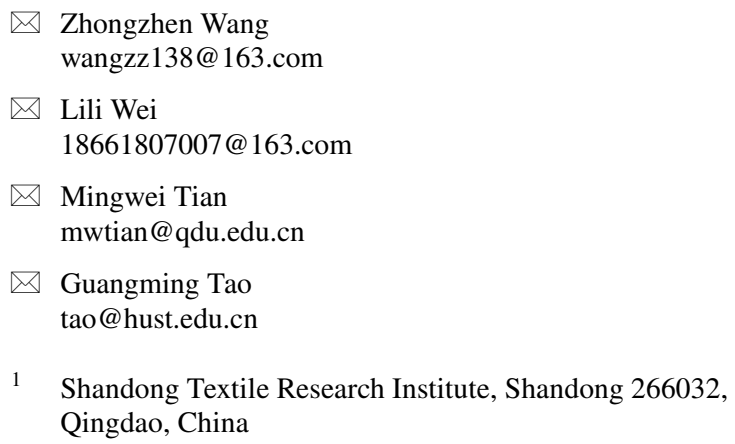

spread before symptoms is possible [6-8]. As of March 7, 2020, 80,695 confirmed cases had been identified in the People's Republic of China, with 3097 deaths [9]. To prevent infection with 2019-nCoV, it is necessary to wear medical protective clothing that meets virus protection standards, such as ANSI/AAMI PB70-2012, EN 14126-2003, GB 19082-2009. Polypropylene spun bond/melt-blown/spunbond (SMS) nonwoven fabric, polymer coated fabrics and polyethylene breathable film/nonwoven composite fabrics

2 Shandong Provincial Key Laboratory of Special Textiles Processing Technology, Shandong 266032, Qingdao, China

3 Research Center for Intelligent and Wearable Technology, College of Textiles and Clothing, State Key Laboratory of Bio-Fibers and Eco-Textiles, Qingdao University, Qingdao 266071, China

4 Wuhan National Laboratory for Optoelectronics and School of Optical and Electronic Information, Huazhong University of Science and Technology, Wuhan 430074, China

5 Department of Nursing, The Affiliated Hospital of Qingdao University, Qingdao 266071, China 
are the main medical protective clothing materials [10], but they have poor breathability and moisture permeability [11]. Sweat moisture accumulation in the inner layer of the fabric causes the wearer discomfort [12]. In addition, it is prone to medical disoperation in long (4-8 h) and high-intensity working conditions. Therefore, evaporative transmittance is considered an important factor concerning the comfort of fabric. Medical protective clothing is developed through the formation a permeable surface on the fabric by coating [13] or configuration of a respirator. However, these strategies undesirably change the comfort of clothing. Superabsorbent fiber with hydrophilic groups has the ability to retain and absorb a large proportion of water [14-19], resulting in quick absorption of sweat and reduction of humidity in the air layer under clothing.

Here, we demonstrate a double-layer medical protective composite structure with a highly hygroscopic inner layer and a protective outer layer. The raw material of the inner layer with superabsorbent performance was prepared from acrylic acid (AA), acrylamide (AM) and polyvinyl alcohol (PVA) via wet spinning to obtain poly(acrylic acid-co-acrylamide)/polyvinyl alcohol (PAAAM/PVA) superabsorbent fibers. Then, the inner layer was prepared from PAAAM/PVA fibers, bamboo pulp fibers (BPF) and ethylene-propylene side by side fibers (ESF) through hot air and needle punching processing. By using polyacrylate pressure-sensitive adhesive, the novel medical protective clothing material was obtained through gluing the superabsorbent layer to the inner surface of strong antistatic polypropylene nonwoven fabric with a breathable polyethylene film. The prepared material exhibited outstanding sweat absorption and retention performance, as well as thermal and moisture comfort, which met the requirements of medical disposable protective clothing. In addition, the sweat absorption and retention, thermal and moisture comfort profile of PAAAM/ PVA fibers were evaluated. This novel medical protective clothing material can significantly reduce the air humidity in clothing and improve the wearing comfort, helping to improve the working status of medical staff, and also provide a reference for the improvement of other types of protective clothing.

\section{Experiment}

\section{Materials}

Acrylic acid (AA), acrylamide (AM), polyvinyl alcohol 1799 (PVA), ammonium persulfate (APS), sodium hydroxide, $N, N$-methylenebisacrylamide (MBA), absolute ethanol, L-histidine hydrochloride monohydrate, sodium chloride, and disodium hydrogen phosphate dehydrate were purchased from Sinopharm Chemical Reagent Co., Ltd., China.
Sodium dihydrogen phosphate dihydrate was bought from Shanghai Runjie Chemical Reagent Co., Ltd., China. Polyacrylate pressure sensitive adhesive was purchased from Shenzhen Hongshengrong Technology Co., Ltd., China. Strong antistatic polypropylene nonwoven fabric covered with breathable polyethylene film (charge amount $<0.2 \mu \mathrm{C}$ / $\mathrm{m}^{2}$, static decay time $<0.3 \mathrm{~s}$ ) was bought from Zibo Dekun Film Co., Ltd., China. Bamboo pulp fiber was obtained from Jilin Chemical Fiber Group Co., Ltd., China. Ethylene-propylene side by side fiber was supplied by Jiangsu Jiangnan High Fiber Co., Ltd., China.

\section{Preparation of PAAAM/PVA fibers}

The schematic diagram of the preparation processes of superabsorbent fibers (PAAAM/PVA fibers) is illustrated in Fig. 1a. In detail, acrylic acid/sodium acrylate solution with $80 \%$ neutralization was prepared in an ice-water bath. The acrylic/sodium acrylate solution with $80 \%$ neutralization, acrylamide, $0.1 \mathrm{wt} \% N, N$-methylenebisacrylamide aqueous solution, $10 \mathrm{wt} \%$ polyvinyl alcohol aqueous solution and deionized water were mixed in a three-necked flask under robust stirring. The mixture was placed in a thermostatic water bath while stirring with a passing $\mathrm{N}^{2}$ atmosphere. The mass ratio of the mixture was set as $\mathrm{w}_{\mathrm{AM}}: \mathrm{w}_{\mathrm{AA}}=1: 4$, $\mathrm{w}_{\mathrm{PVA}}: \mathrm{w}_{\mathrm{AA}+\mathrm{AM}}=1: 4, \quad \mathrm{w}_{\mathrm{MBA}}: \mathrm{w}_{\mathrm{AA}}+\mathrm{AM}=0.03: 50$, $(\mathrm{AA}+\mathrm{AM}+\mathrm{PVA}) \mathrm{wt} \%=18 \%$. When the water bath was heated to $60{ }^{\circ} \mathrm{C}, 4 \mathrm{wt} \%$ ammonium persulfate aqueous solution was slowly added to the mixture drop by drop with a mass ratio of $\mathrm{w}_{\mathrm{APS}}: \mathrm{w}_{\mathrm{AA}}+\mathrm{AM}=0.1: 25$, and the solution remained at $60{ }^{\circ} \mathrm{C}$ for $1 \mathrm{~h}$. The water bath was then heated to $70{ }^{\circ} \mathrm{C}$ and stirring continued for $1 \mathrm{~h}$ until $\mathrm{P}(\mathrm{AA}-\mathrm{co}-\mathrm{AM}) /$ PVA polymer solution formed. The product was then cooled to room temperature.

The mixture solution of $\mathrm{P}(\mathrm{AA}-\mathrm{co}-\mathrm{AM}) / \mathrm{PVA}$ was then spun into fibers using a laboratorial wet spinning system. The solution was added into the spinning pot of the wet spinning system and stood for $24 \mathrm{~h}$ to defoam. The $50 \%$ $(\mathrm{V} / \mathrm{V})$ ethanol solution at $30^{\circ} \mathrm{C}$ was employed as the coagulation bath to obtain $\mathrm{P}(\mathrm{AA}-\mathrm{co}-\mathrm{AM}) / \mathrm{PVA}$ fibers. The prepared fiber was dried in a hot-drawing oven at $45^{\circ} \mathrm{C}$ for $5 \mathrm{~min}$, and then cross-linked in an oven at $105^{\circ} \mathrm{C}$ for $20 \mathrm{~min}$ to obtain poly(acrylic acid-co-acrylamide)/polyvinyl alcohol (PAAAM/PVA) superabsorbent fibers.

\section{Preparation of Highly Hygroscopic and Strong Antistatic Medical Protective Composite Nonwoven Fabric}

The preparation process of the highly hygroscopic and strong antistatic medical protective composite nonwoven fabric is shown in Fig. 1b. An AS181A carding machine was used to fully mix PAAAM/PVA fiber/BPF/ESF with a mass 


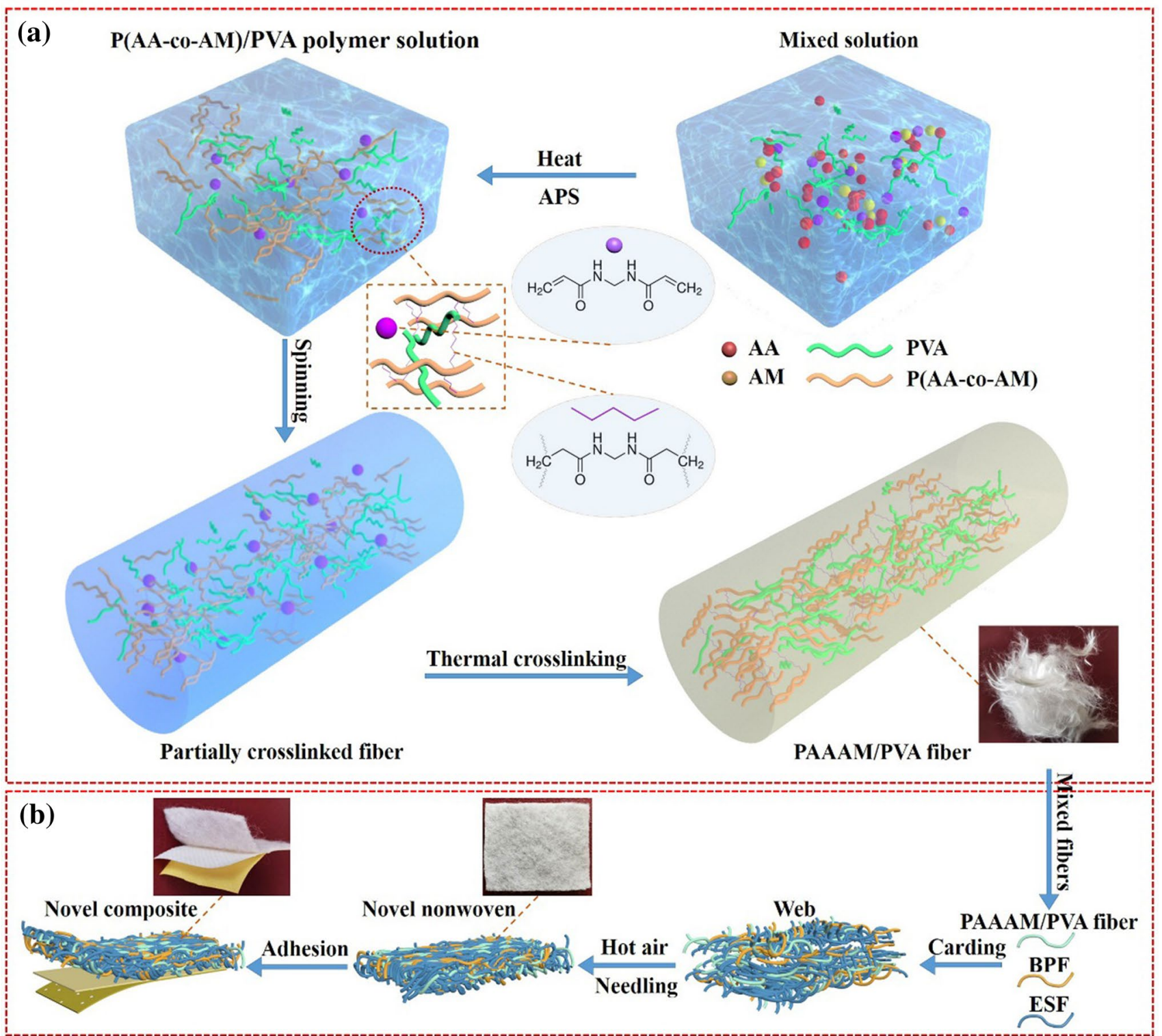

Fig. 1 Preparation processes of $\mathbf{a}$ PAAAM/PVA fibers and $\mathbf{b}$ highly hygroscopic and strong antistatic medical protective clothing material

ratio of 25/15/60 into a web. The fiber web was heat-bonded at $140{ }^{\circ} \mathrm{C}$ in an electric blast constant-temperature oven for $25 \mathrm{~min}$, then needle punched to obtain a highly hygroscopic nonwoven fabric.

The novel medical protective composite nonwoven fabric was obtained through gluing the highly hygroscopic nonwoven fabric to the inner surface of the strong antistatic polypropylene nonwoven fabric covered with a breathable polyethylene film by polyacrylate pressure-sensitive adhesion.

\section{Characterization}

The surface morphology of PAAAM/PVA fibers was characterized by SEM (TESCAN VEGA3, Kohoutovice, Czech
Republic). The surface structure of the resultant fibers was measured by FTIR (Nicolet 5700, Madison, USA) with a spectral range of $400-4000 \mathrm{~cm}^{-1}$. A fiber fineness analyzer (YG002C, Ningbo, China) was used to study the swelling behavior of the fibers.

\section{Sweat Absorption and Retention of Composite Nonwoven Fabric}

Acid and alkaline sweats were prepared according to ISO 105-E04:2013. The absorption rate of PAAAM/PVA fibers or materials was measured by the tea bag method [20]. $2.00 \mathrm{~g}$ of dried fibers or $5.00 \mathrm{~g}$ dried material was immersed into sweat at $37^{\circ} \mathrm{C}$ for different durations. A 300-mesh nylon 
mesh bag was used to filtrate. The fibers or materials were weighed when dripping had ceased [21,22].

The retention rate was determined by the pressing loss method [23-25]. The fibers or materials were weighed at room temperature after having fully absorbed the sweat. The fibers were then distributed as evenly as possible in a $\varphi 100 \mathrm{~mm}$ petri dish covered with a 300-mesh nylon mesh. A load of $200 \mathrm{~g} / \mathrm{m}^{2}$ was applied for a certain period and then the sample was weighed. The materials were put into a $\varphi 150 \mathrm{~mm}$ petri dish and a load of $200 \mathrm{~g} / \mathrm{m}^{2}$ was applied, then put them in a polyethylene bag as a whole to seal, and placed them in an oven at $37^{\circ} \mathrm{C}$ with different times. The results for the novel material were compared with those for the conventional material (strong antistatic polypropylene nonwoven fabric covered with breathable polyethylene film).

\section{Hygroscopicity of Composite Nonwoven Fabric}

In order to evaluate the hygroscopicity of the novel material, self-made equipment was developed. In detail, $100 \mathrm{~g}$ of distilled water was added into a $150 \mathrm{~mL}$ beaker, and then the beaker was sealed with the novel material and the conventional material, respectively. These two beakers were placed on a heating plate at $80^{\circ} \mathrm{C}$, and the water mist on the cup wall was observed and compared. The moisture absorption rate was calculated by measuring the weight differences of the covered materials at different time points.

\section{Thermal and Moisture Comfort of Composite Nonwoven Fabric}

The moisture permeability and thermal resistance were used to evaluate the thermal and moisture comfort of the novel material. The hygroscopic method was used to measure the moisture permeability $[26,27]$, the test conditions were at $37^{\circ} \mathrm{C}$ and $90 \%$ humidity with air flow velocity $0.3 \mathrm{~m} / \mathrm{s}$, and the polyethylene film was facing up. The thermal resistance of the novel material was tested using a flat-type fabric thermal insulation instrument [28] according to ISO 11092:2014. The results of the novel material were compared with those of the conventional material.

\section{Results and discussion}

The morphology of PAAAM/PVA fibers is shown in Fig. 2. As shown in the SEM image of Fig. 2a, b, microscale grooves and strips can be obviously observed on the PAAAM/PVA fiber surface. These grooves and strips increase the contact area between fiber and water, leading to an increase in water absorption. As can be seen in Fig. 2c, $\mathrm{d}$, microscale pores with a diameter of less than $1 \mu \mathrm{m}$ are distributed inside the fiber. Water molecules can penetrate into the fiber through these microscale pores, resulting in an increase in water absorption and retention. Microscale protrusions can be seen on the surface and cross section of the fiber, which illustrates a micro phase separation structure of P(AA-co-AM) and polyvinyl alcohol.

The FTIR spectrum of PAAAM/PVA fibers is shown in Fig. 2e. The peak at $3413 \mathrm{~cm}^{-1}$ is a typical peak formed by

(b)

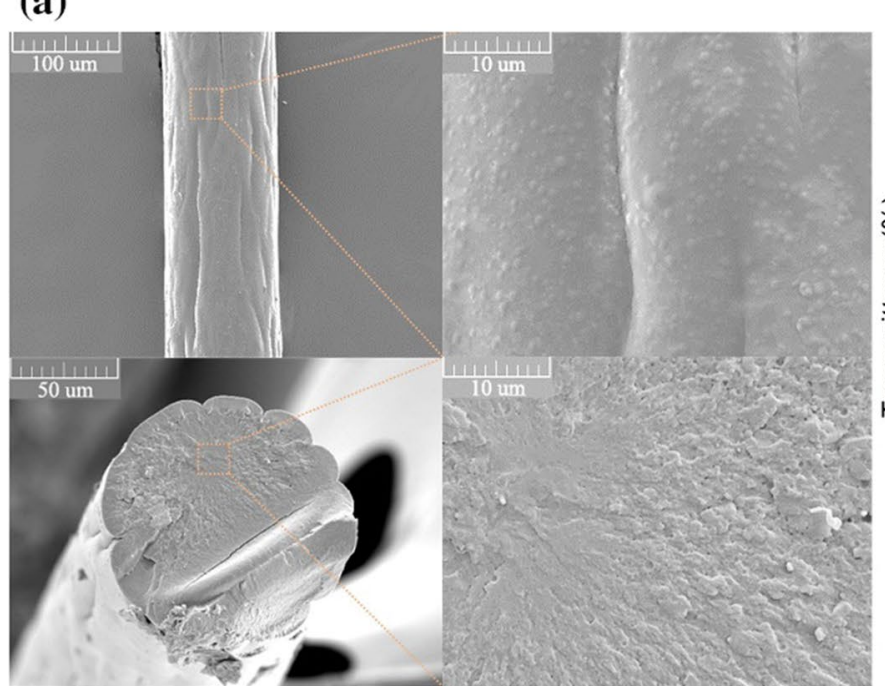

Fig. 2 SEM images of PAAAM/PVA fibers a the longitudinal surface and $\mathbf{b}$ high magnification view, $\mathbf{c}$ the cross-section and $\mathbf{d}$ high magnification view. e FTIR spectra of PAAAM/PVA fibers 
the stretching vibration of the hydroxide bond. The peak at about $2935 \mathrm{~cm}^{-1}$ corresponds to $\mathrm{C}-\mathrm{H}$ stretching vibration. The vibration peaks at 1621,1560 and $1328 \mathrm{~cm}^{-1}$ are formed by $\mathrm{C}=\mathrm{O}$ stretching, $\mathrm{N}-\mathrm{H}$ bending and $\mathrm{C}-\mathrm{N}$ stretching vibrations of acylamino, respectively. The peak at about $1408 \mathrm{~cm}^{-1}$ corresponds to $\mathrm{COO}^{-}$stretching vibration. The vibration peak at $1104 \mathrm{~cm}^{-1}$ is formed by $\mathrm{C}-\mathrm{O}$ stretching vibration of polyvinyl alcohol [29]. The characteristic peaks of PAAAM/PVA fibers demonstrate that there are both acrylic-co-acrylamide and polyvinyl alcohol.
The swelling behavior of PAAAM/PVA fibers is illustrated in Fig. 3a. The structure of PAAAM/PVA fibers is a lightly cross-linked macromolecular network. The network structure with a large number of hydrophilic groups such as $-\mathrm{COOH}$ and $-\mathrm{COONa}$ consists of chemical crosslinks and intertwined macromolecular chains. Macromolecular chains in fiber are tightly contracted together under dry conditions. However, when the fiber contacts water, the - $\mathrm{COONa}$ group dissociates with $-\mathrm{COO}^{-}$fixed in the macromolecular chain to generate an electrostatic repulsive force leading
Figure 3 a Swelling behavior and mechanism of PAAAM/ PVA fibers in different liquids. b The absorption rate-time curve of PAAAM/PVA fibers in alkaline and acid sweats. c The retention rate-time curve of PAAAM/PVA fibers in alkaline and acid sweats. d The absorption rate-time curve of NM and $\mathrm{CM}$ in alkaline and acid sweats. e The retention rate-time curve of NM and $\mathrm{CM}$ in in alkaline and acid sweats.
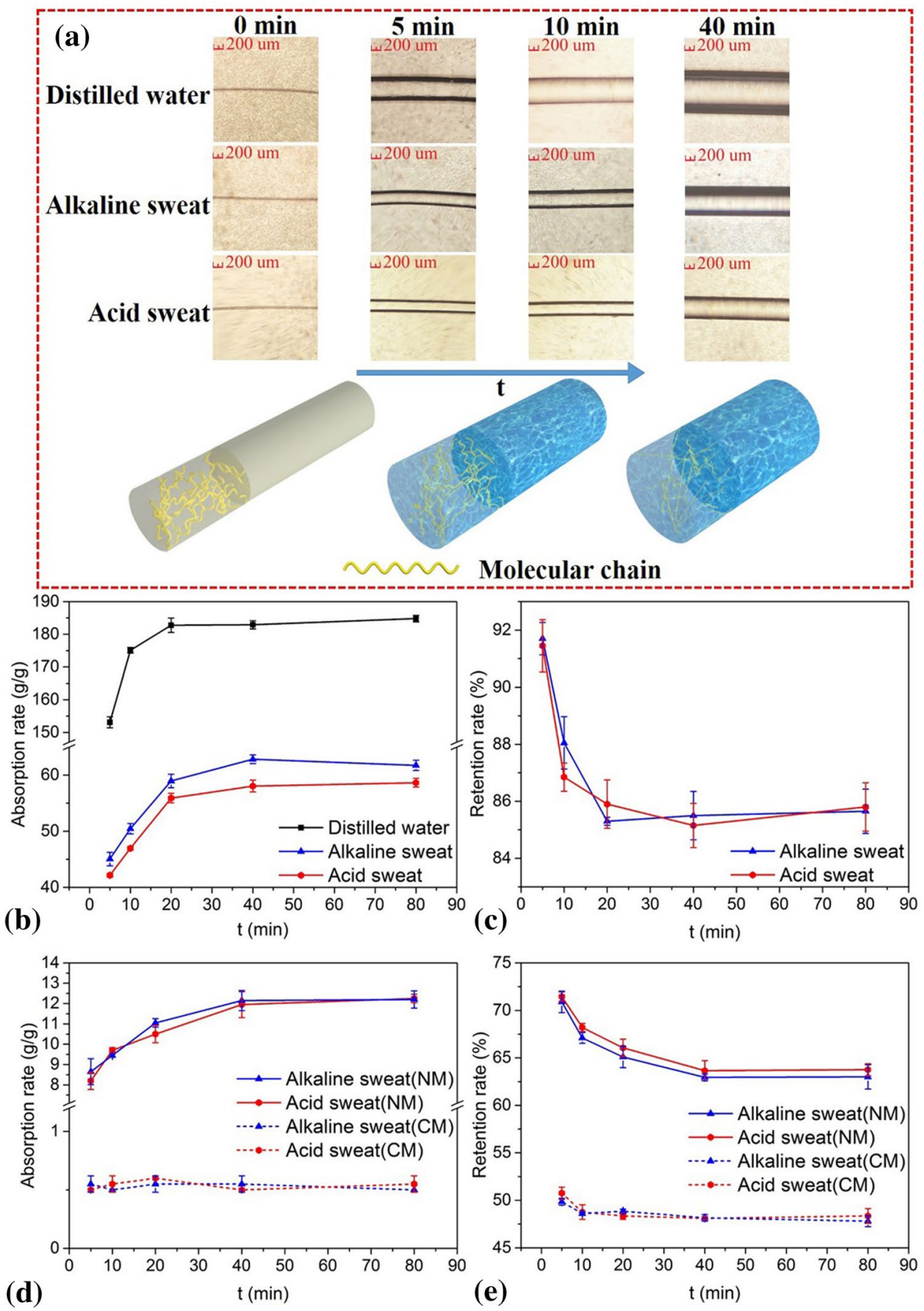
to expansion of the network structure. Meanwhile, most of $\mathrm{Na}^{+}$is trapped inside the network due to the increasing of osmotic pressure [30]. So, the fiber can absorb water and swell. With the increasing absorbance of water, the osmotic pressure reaches equilibrium. Meanwhile, the expansion of the network is also limited by chemical bonds and elastic shrinkage of the network structure. As a result, the fiber has the ability to absorb and retain water to a certain extent.

The absorption rate-time curves of PAAAM/PVA fibers in different solutions can be seen in Fig. 3b. The three curves exhibit the same tendency and the maximum sweat absorption rates of PAAAM/PVA fibers could reach $62.9 \mathrm{~g} / \mathrm{g}$ and $58.1 \mathrm{~g} / \mathrm{g}$ at $40 \mathrm{~min}$ in alkaline and acid sweats respectively, which are much lower than those of distilled water. This is mainly due to the bond between water molecules and hydrophilic groups on molecular chains of PAAAM/PVA being inhibited by ions in sweat. Therefore, the osmotic pressure inside and outside of the network structure reduces, causing a reduction of water molecules entering the fiber. As a result, the maximum liquid absorption rate reduces. It has little effect on the maximum liquid absorption of PAAAM/PVA fibers in acid sweat and alkaline sweat due to weak acidity and basicity. PAAAM/PVA fibers reach the fastest liquid absorption rate at $5 \mathrm{~min}$, which is the result of the interaction of hydrophilic groups and osmotic pressure. The liquid absorption rate decreases with reduction in osmotic pressure and the shrinking force caused by the network expansion.

Retention of PAAAM/PVA fibers is shown in Fig. 3c. Sweat retention rates of PAAAM/PVA fibers could reach $85.6 \%$ and $85.8 \%$ at $40 \mathrm{~min}$ in alkaline and acid sweats, respectively. The main sweat loss of the fibers appears within $10 \mathrm{~min}$, because water is easily squeezed out on fiber surfaces and among fibers under pressure. Then, sweat loss decreases due to difficulty in the disruption of the bond between water and the hydrophilic group.

The comparison of the sweat absorption between the novel material (NM) and the conventional material (CM) is shown in Fig. 3d. The maximum sweat absorption rates of the NM reach $12.2 \mathrm{~g} / \mathrm{g}$ and $12.3 \mathrm{~g} / \mathrm{g}$ at $40 \mathrm{~min}$ in alkaline and acid sweats, respectively, much higher rates than for the CM. It can be seen that PAAAM/PVA fibers and bamboo pulp fibers [31,32] can absorb a large amount of liquid due to the hydrophilic groups and structures. Furthermore, the densely entangled network structure and internal voids of the NM result in a good physical adsorption effect on sweat. The NM reaches the fastest sweat absorption rate at $5 \mathrm{~min}$. Then, the rate decreases as the fiber absorption gradually approaches saturation and the expanded PAAAM/PVA fibers occupy the internal voids.

The sweat retentions between the NM and CM are compared and illustrated in Fig. 3e. It can be seen that the sweat retention rates of the NM reach $63.0 \%$ and $63.8 \%$ in alkaline and acid sweats, respectively, which are significantly higher than those of the CM. Meanwhile, both materials have fastest sweat loss rates within $5 \mathrm{~min}$. The sweat in the voids of the NM is absorbed by physical action resulting in a poor binding force; it is easily diffused or squeezed out under a certain pressure, resulting in faster sweat loss in the first $5 \mathrm{~min}$. It is difficult to disrupt the bond between water and hydrophilic groups, and the moisture is absorbed by the NM again with sweat evaporating inside of the polyethylene bag. As a result, the sweat loss rate decreases in the later period and the retention rate gradually reaches stability. Compared with the NM, the structure of the CM is denser. Once water molecules enter into the fiber and nonwoven fiber, it is difficult to squeeze it out. That is the reason why the CM has a certain liquid retention rate.

In addition, a moisture absorption experiment was run and thermal moisture comforts between the NM and the $\mathrm{CM}$ were compared. The moisture absorption processes of the NM and CM can be seen in Fig. 4a. Both materials (NM and $\mathrm{CM}$ ) can block the release of water vapor from the beaker. Water mist on the beaker covered with the CM can be obviously observed at $5 \mathrm{~min}$, and the formed water droplets slipped down at $10 \mathrm{~min}$. On the contrary, for the NM case, the beaker surface is almost transparent at $5 \mathrm{~min}$. Water mist only appears on the beaker surface at $30 \mathrm{~min}$, which illustrates that the humidity is lower. Therefore, we propose that the highly hygroscopic functional layer of the NM can efficiently absorb water vapor in the air for a long time and reduce the humidity of the air, protecting medical staff form pathogen damage. Furthermore, the moisture absorption rates of the NM and CM are calculated and shown in Fig. 4b. The curves show the moisture absorption rate of the NM dramatically increases along with heating time, reaching $1.04 \mathrm{~g} / \mathrm{h}$. For the $\mathrm{CM}$ case, the moisture absorption reaches $0.53 \mathrm{~g} / \mathrm{h}$. The results indicate that the high moisture absorption functional layer has a strong ability to absorb water vapor and lasts a long time. But PAAAM/ PVA fibers in the surface layer gradually become gelatinous after absorbing moisture, which hinders the entry of water vapor. Therefore, the increase in moisture absorption rate slows down after $2 \mathrm{~h}$.

It can be seen from Fig. $4 \mathrm{c}$ that the moisture permeability of the NM reaches $12,638.5 \mathrm{~g} /\left(\mathrm{m}^{2} \mathrm{~d}\right)$, which is $307.6 \%$ that of the CM. Medical protective clothing has strict requirements for filtration efficiency of pathogens through the formation of an impermeable surface on the fabric by coating or laminating, resulting in a low moisture permeability. However, the NM absorbs a large amount of water vapor to keep a low humidity in the air layer under the clothing by using the strong hygroscopicity and liquid retention of PAAAM/ PVA fibers as well as the porous structure of the novel nonwoven fabric. The thermal resistance of the NM is higher than that of the CM due to the greater thickness of the NM. The thermal insulation effect of the novel nonwoven fabric 


\section{(a)}
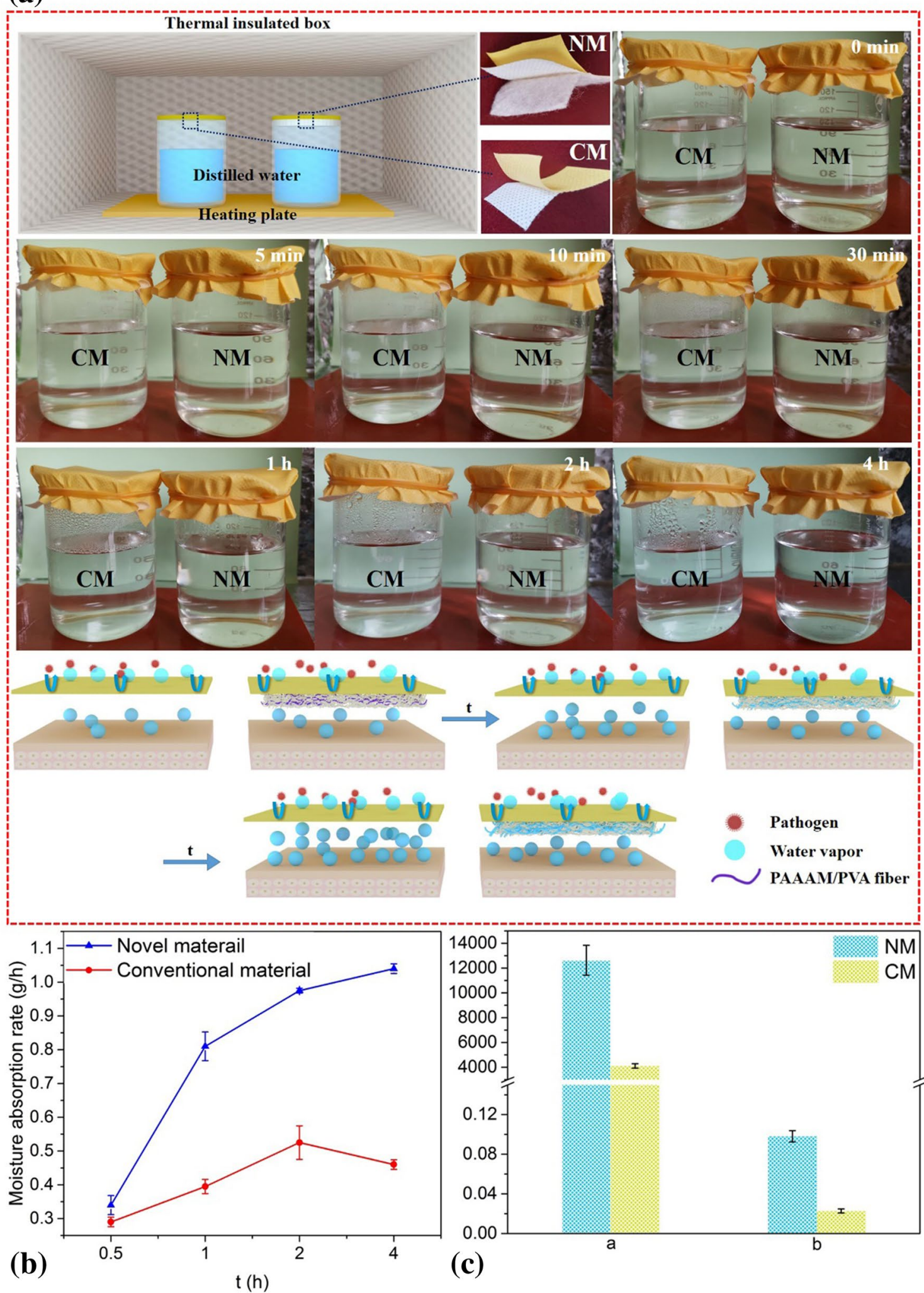

(c)

Figure 4 a Simulated moisture absorption experiment. b Moisture absorption rate of NM and CM. c Thermal and moisture comfort comparison between NM and CM (a Water vapor permeability, $g /\left(\mathrm{m}^{2} \mathrm{~d}\right)$; b Thermal resistance, $\left.\mathrm{m}^{2} \mathrm{~K} / \mathrm{W}\right)$. 
is better than that of the $\mathrm{CM}$ due to its loose and porous structure [33]. As a result, the NM can be used in parts of protective clothing to ensure low thermal resistance.

\section{Conclusions}

PAAAM/PVA superabsorbent fibers were prepared from acrylic acid, acrylamide and polyvinyl alcohol via wet spinning, achieving high hygroscopicity and water retention. The maximum sweat absorption rate and retention rate of PAAAM/PVA fibers were $62.9 \mathrm{~g} / \mathrm{g}$ and $85.8 \%$, respectively. The absorption rate of the novel material had little difference in alkaline and acid sweats, with a maximum value of $12.3 \mathrm{~g} / \mathrm{g}$. The maximum sweat retention rate of the novel material $(63.8 \%)$ was higher than that of the conventional material. The maximum moisture absorption rate of the novel material reached $1.04 \mathrm{~g} / \mathrm{h}$, more than that of the control case (only $0.53 \mathrm{~g} / \mathrm{h}$ ). The moisture permeability of the novel material reached $12,638.5 \mathrm{~g} /\left(\mathrm{m}^{2} \mathrm{~d}\right)$, which was $307.6 \%$ that of the conventional material. The novel medical protective clothing material has excellent hygroscopicity and can significantly improve the comfort of medical staff. However, the thermal resistance of the novel material was slightly higher than that of the conventional material. Therefore, the novel material can be used in parts of the protective clothing to ensure low thermal resistance.

Acknowledgements This work was supported by the Science and technology guidance project plan of China National Textile And Apparel Council (2017006), Natural Science Foundation of Shandong Province of China (ZR2018QEM004), Research and Development Program of Shandong Province of China (Grant Nos. 2019GGXI02022, 2019JZZY010340, and 2019JZZY010335), Anhui Province Special Science and Technology Project (201903a05020028), and Shandong provincial universities youth innovation technology plan innovation team (2020KJA013).

\section{References}

1. World Health Organization. https://www.who.int/zh/dg/speeches/ detail/who-director-general-s-statement-on-ihr-emergency-commi ttee-on-novel-coronavirus-(2019-ncov).

2. Zhu N, Zhang DY, Wang WL, Li XW. A novel coronavirus from patients with pneumonia in China, 2019. $N$ Engl J Med. 2020;382:727-33.

3. Wu JT, Leung K, Leung GM. Nowcasting and forecasting the potential domestic and international spread of the 2019-nCoV outbreak originating in Wuhan, China: a modelling study. Lancet. 2020;395:689-97.

4. Chan JFW, Yuan SF, Kok KH, To KKW, Chu H. A familial cluster of pneumonia associated with the 2019 novel coronavirus indicating person-to-person transmission: a study of a family cluster. Lancet. 2020;395:514-23.

5. Chen NS, Zhou M, Dong X, Qu JM, Gong FY. Epidemiological and clinical characteristics of 99 cases of 2019 novel coronavirus pneumonia in Wuhan, China: a descriptive study. Lancet. 2020;395:507-13.

6. Chen HJ, Guo JJ, Wang C, Luo F, Yu XC. Clinical characteristics and intrauterine vertical transmission potential of 2019NCOV infection in nine pregnant women: a retrospective review of medical records. Lancet. 2020;395:809-15.

7. Holshue ML, DeBolt C, Lindquist S, Lofy KH, Wiesman J. First case of 2019 novel coronavirus in the United States. $N$ Engl $J$ Med. 2020;382:929-36.

8. Guan W, Ni Z, Hu Y, et al. Clinical characteristics of coronavirus disease 2019 in China. N Engl J Med. 2020;382(18):1708-20.

9. National Health Committee of the People's Republic of China. https://www.nhc.gov.cn/xcs/yqfkdt/202003/b4c328ff60874b9 9ba6ce8caf827987b.shtml.

10. Wang FM, Gao CS. Protective clothing, managing thermal stress. Cambridge: Woodhead Publishing Limited; 2014.

11. Zwolińska M, Bogdan A. Impact of the medical clothing on the thermal stress of surgeons. Appl Ergon. 2012;43:1096-104.

12. Smith CJ, Havenith G. Body mapping of sweating patterns in athletes: a sex comparison. Med Sci Sport Exerc. 2012;44:2350.

13. Hao XM, Zhang JC, Guo YH. Study of new protective clothing against SARS using semi-permeable PTFE/PU membrane. Eur Polym J. 2004;40:673-8.

14. Aminyan R, Bazgir S. Fabrication and characterization of nanofibrous polyacrylic acid superabsorbent using gasassisted electrospinning technique. React Funct Polym. 2019; 141:133-44.

15. Wang M, Li X, Zhang TH, Deng L, Li PY. Eco-friendly poly(acrylic acid)-sodium alginate nanofibrous hydrogel: a multifunctional platform for superior removal of $\mathrm{Cu}(\mathrm{II})$ and sustainable catalytic applications. Colloids Surf A. 2018;558:228-41.

16. Lim KY, Yoon KJ, Kim BC. Highly absorbable lyocell fiber spun from celluloses/hydrolyzed starch-g-PAN solution in NMMO monohydrate. Eur Polym J. 2003;39:2115-200.

17. Zhai TL, Zheng QF, Cai ZY, Xia HS, Gong SQ. Mechanism study of heat stabilization of polyacrylonitrile nanofibers against alkaline hydrolysis. Polym Degrad Stab. 2014;105:80-5.

18. Jin X, Hsieh YL. pH-responsive swelling behavior of poly(vinyl alcohol)/poly(acrylic acid) bi-component fibrous hydrogel membranes. Polymer. 2005;46:5149-60.

19. Sweeney IR, Miraftab M, Collyer G. Absorbent alginate fibres modified with hydrolysed chitosan for wound care dressingsII. Pilot scale development. Carbohydr Polym. 2014;102:920-7.

20. Wu F, Zhang Y, Liu L, Yao JM. Synthesis and characterization of a novel cellulose- $g$-poly(acrylic acid-co-acrylamide) superabsorbent composite based on flax yarn waste. Carbohydr Polym. 2012;87:2519-25.

21. Ma ZH, Li Q, Yue QY, Gao BY, Xu X. Synthesis and characterization of a novel super-absorbent based on wheat straw. Bioresour Technol. 2011;102:2853-8.

22. Islam MS, Rahaman MS, Yeum JH. Electrospun novel super-absorbent based on polysaccharide-polyvinyl alcoholmontmorillonite clay nanocomposites. Carbohydr Polym. 2015; 115:69-77.

23. Jassal M, Chattopadhyay R, Ganguly D. Synthesis and Characterization of Sodium Acrylate and 2-Acrylamido-2-Methylpropane Sulphonate (AMPS) Copolymer Gels. Fibers Polym. 2004;5:95-104.

24. Ramazani-Harandi MJ, Zohuriaan J, Yousefi AA, Ershad-Langroudi A, Kabiri K. Rheological determination of the swollen gel strength of superabsorbent polymer hydrogels. Polym Test. 2006; $25: 470-4$.

25. Jin ZF, Asako Y, Yamaguchi Y, Yoshida H. Thermal and water storage characteristics of superabsorbent polymer gel which absorbed aqueous solution of calcium chloride. Int J Heat Mass Transf. 2000;43:3407-15. 
26. Richter J, Staněk K. Measurements of water vapour permeabilitytightness of fibreglass cups and different sealants and comparison of $\mu$-value of gypsum plaster boards. Proc Eng. 2016;151:277-83.

27. Mustapha R, Zoughaib A, Ghaddar N, Ghali K. Modified upright cup method for testing water vapor permeability in porous membranes. Energy. 2020;195:117057.

28. Wang X, Zhao Y, Li WB, Wang H. Effect of surface modifications on the thermal and moisture behavior of wool fabric. Appl Surf Sci. 2015;342:101-5.

29. Abral H, Atmajaya A, Mahardika M, Hafizulhaq F. Effect of ultrasonication duration of polyvinyl alcohol (PVA) gel on characterizations of PVA film. J Mater Res Technol. 2020;9:2477-86.

30. Budtova T, Navard P. Swelling kinetics of a polyelectrolyte gel in water and salt solutions. Coexistence of swollen and collapsed phases. Macromolecules. 1998;31:8845-50.

31. Tausif M, Ahmad F, Hussain U, Basit A, Hussain T. A comparative study of mechanical and comfort properties of bamboo viscose as an eco-friendly alternative to conventional cotton fibre in polyester blended knitted fabrics. J Clean Prod. 2015;89:110-5.

32. Lu TJ, Liu SM, Jiang M, Xu XL, Wang Y. Effects of modifications of bamboo cellulose fibers on the improved mechanical properties of cellulose reinforced poly(lactic acid) composites. Compos Part B Eng. 2014;6:191-7.

33. Wazna ME, Fatihi ME, Bouari AE, Cherkaoui O. Thermo physical characterization of sustainable insulation materials made from textile waste. J Build Eng. 2017;12:196-201.

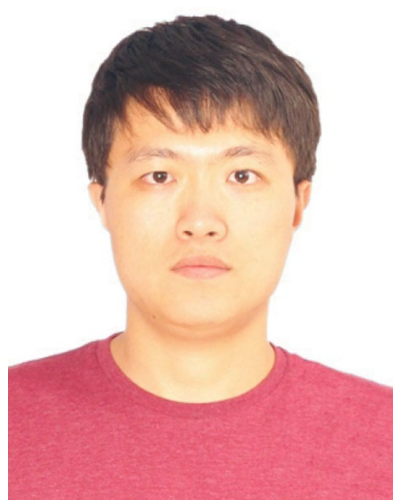

Lin Yang is an engineer of Shandong Textile Research Institute. $\mathrm{He}$ received his master degree from Qingdao University. His main research directions include: (1) Preparation and application research of medical nonwoven materials; (2) Structure and function design of hydrogel fibers.

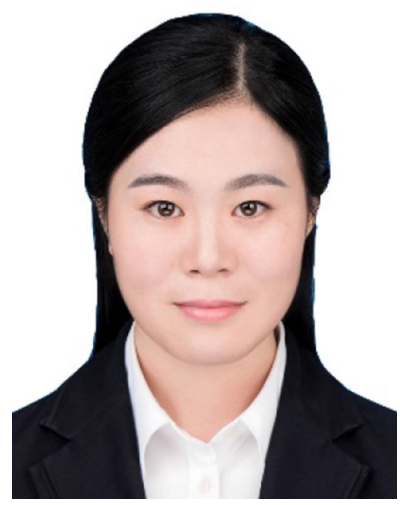

Hong Liu is a lecturer of the college of Textile and clothing, Qingdao University. She received her Ph.D in Fashion and clothing engineering from Donghua University. Her research interests include the smart wearable clothing structure design, functional fabrics based on graphene.

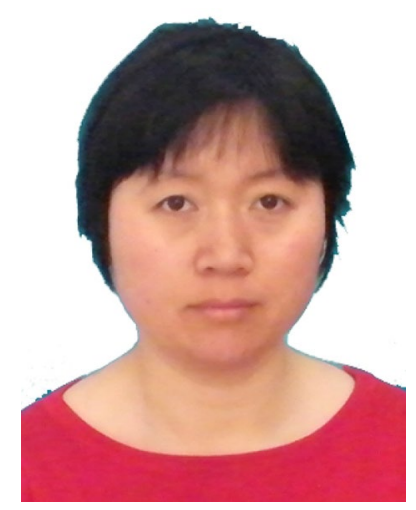

Shuai Ding is a senior engineer of Shandong Textile Research Institute. She received her master degree from Qingdao University of Science \& Technology. Her research interests include: (1) Conductive fiber and intelligent textiles; (2) Functional modification of textiles.

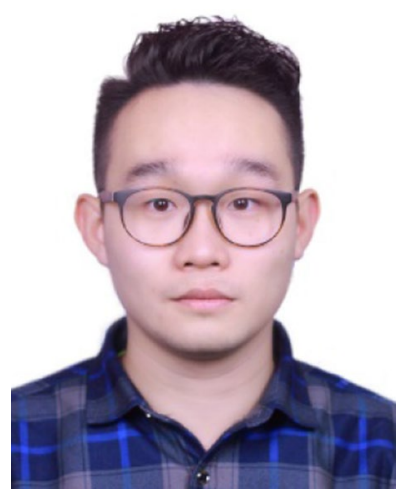

Wu Jiawei received the M.S degree from the School of Polymer Science and Engineering, College of Technology at Hubei Engineering University, China. $\mathrm{He}$ is currently as engineer at school of Optical and Electronic Information in Huazhong University of Science and Technology. His research interests mainly include the smart wearable fabric based on thermoregulation.

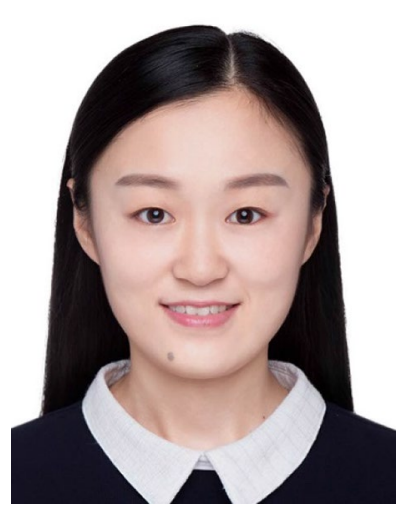

Yan Zhang master graduated from Perking Union Medical College and is currently working in the Affiliated Hospital of Qingdao University. Her research focus on patients care and application of fiber materials in clinical nursing to improve nursing care quality.

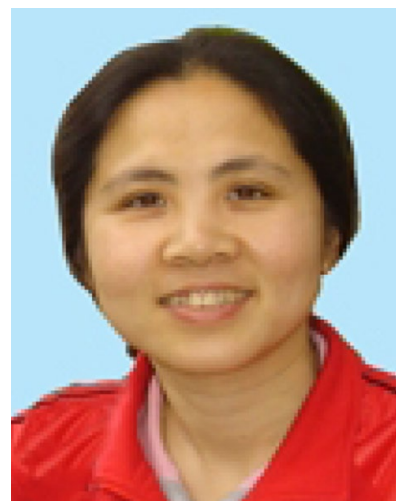

Zhongzhen Wang is a professor of engineering of Shandong Textile Research Institute. She received master degree from Henan University. Her main research directions include: (1) Cattail fiber multi-functional oilabsorbing nonwoven materials; (2) Biodegradable composite nonwoven materials for soilless culture; (3) Nano anti-ultraviolet functional textiles. 


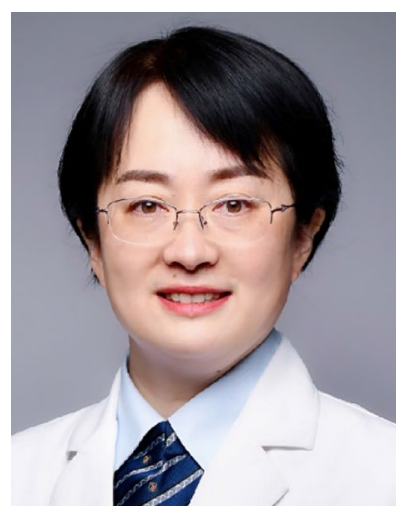

Lili Wei is a professor of School of nurse, Qingdao University, postgraduate in Perking Union Medical College and $\mathrm{PhD}$ in Qingdao University. Her current research interests cover clinical nursing, nursing management, nursing quality improvement, especially the improvement of patient-centered nursing quality.

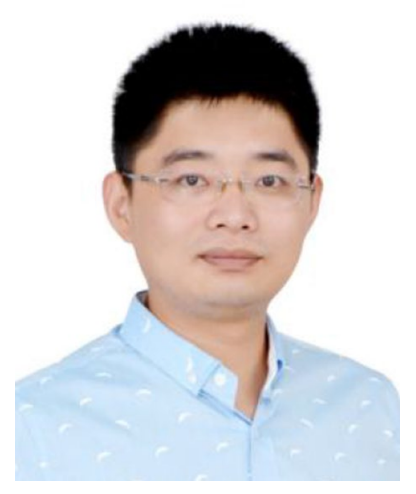

Mingwei Tian is currently associate Professor of College of Textiles and Clothing at Qingdao University and served as the vice dean of College of Textiles and Clothing at QDU. Dr. Tian's research focuses on field of new fibrous materials and smart textiles, wearable devices, etc. Dr. Tian has authored over 100 research papers (56 SCI index, H-Index 13), 18 patents. Dr. Tian has served on the members of the textile teaching instruction committee of Ministry of Education, American fiber society and senior member of Chinese Textile Engineering Society.

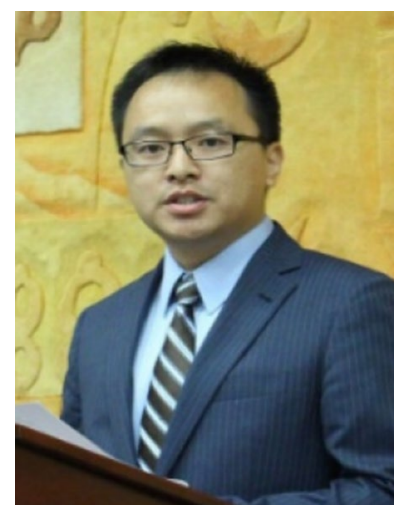

Guangming Tao is a Professor at Wuhan National Laboratory for Optoelectronics and the School of Optical and Electronic Information at Huazhong University of Science and Technology (HUST). He is the Director of Center of Advanced Functional Fibers (CAFF) and the Director of Man-Machine Lab (2M lab) at HUST. He received his Ph.D. degree (2014) in optics from the University of Central Florida. He was a Research Scientist/Sr. Research Scientist at The College of Optics \& Photonics (CREOL), University of Central Florida from 2014 to 2017. Dr. Tao has published about 40 scientific papers, has given in excess of 45 invited lectures/colloquia or keynote talk, and has co-organized more than 10 national and international conferences and symposia, including Symposium SM2 (Advanced multifunctional fibers and textiles) at 2017 Spring MRS Meeting, Symposium J (Multifunctional and multimaterial fibers) at 2017 International Conference on Advanced Fibers and Polymer Materials, etc. He has years of research experience in optical sciences and engineering in academia, industry, and government institutes with expertise in the areas of functional fibers, smart fabric, man-machine interactions, infrared optical fibers and in-fiber structured particles generation. 